\title{
Association between mean platelet volume and disease severity in patients with psoriasis and psoriatic arthritis
}

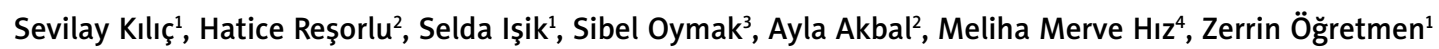 \\ ${ }^{1}$ Department of Dermatology, School of Medicine, Canakkale Onsekiz Mart University, Canakkale, Turkey \\ 2Department of Physical Medicine and Rehabilitation, School of Medicine, Canakkale Onsekiz Mart University, Canakkale, Turkey \\ ${ }^{3}$ Department of Public Health, School of Medicine, Canakkale Onsekiz Mart University, Canakkale, Turkey \\ ${ }^{4}$ Department of Medical Biology, Faculty of Medicine, Canakkale Onsekiz Mart University, Canakkale, Turkey
}

Adv Dermatol Allergol 2017; XXXIV (2): 126-130

DOI: https://doi.org/10.5114/ada.2017.67076

\begin{abstract}
Introduction: Mean platelet volume (MPV) is an important marker that shows the activation and function of the platelets, which is effective in the inflammatory diseases.

Aim: To show the relationship between MPV and the development of psoriatic arthritis (PA) in patients with psoriasis vulgaris (PV) and the correlation between MPV and psoriasis severity score (PASI).

Material and methods: Our study included 116 patients with psoriatic arthritis (68 female, 48 male) and 41 patients in the psoriasis group (19 female, 22 male) and 90 subjects in the control group ( 55 female, 35 male). The demographic data of the patients, duration of disease, PASI, the nature of the disease were evaluated retrospectively. Results: Mean platelet volume levels of both the PV group $(8.79 \pm 0.86 \mathrm{fl})$ and the PA group $(9.18 \pm 1.26 \mathrm{fl})$ were significantly higher compared to the control group $(8.42 \pm 0.74 \mathrm{fl})$. There was a weak statistically positive correlation between the PASI and the MPV according to the correlation analysis $(r=0.165 ; p=0.046)$.

Conclusions: Our results show that MPV may be helpful as an indicator of the clinical course of PV and PA. In this regard, that study should be supported by prospective studies to find strong correlations.
\end{abstract}

Key words: mean platelet volume, psoriasis, psoriatic arthritis, mean platelet volume, psoriasis severity score.

\section{Introduction}

Psoriasis is a chronic inflammatory disease observed at a rate of $0.91-8.5 \%$ in the adult population. It is an ongoing progressive disease accompanied by periods of attacks and remissions, which is caused by immunologically mediated mechanisms [1, 2]. Psoriasis is related to ulcerative colitis, gastrointestinal disorders such as Crohn's disease and in the group of rheumatic diseases, such as rheumatoid arthritis and ankylosing spondylitis. Psoriasis is defined as an immune-mediated inflammatory disease (IMID) [3, 4].

Psoriatic arthritis is an inflammatory arthritis that can occur both in the peripheral joints and axial skeleton and is seen in $6-42 \%$ of psoriasis patients that have a negative rheumatoid factor $[5,6]$. It is reported that arthritis may develop in $13-71 \%$ of patients before the emergence of skin lesions even though in most patients, arthritis develops after psoriasis skin lesions occur $[7,8]$.
A variety of cytokines, chemokines and other inflammatory mediators released from activated platelets affect the immune response regulation [9]. Inflammatory markers such as the erythrocyte sedimentation rate (ESR) and C-reactive protein (CRP) not always correlate with the disease activity [5], thus a new marker "MPV" will be helpful in evaluating the course of the diseases. Mean platelet volume (MPV) is an indicator of platelet activation and function. The size of the platelets and the production rate of bone marrow reflects the function and activation of the platelets [10-12]. Although MPV levels have been studied in many diseases, there are limited data about it in patients with psoriasis and psoriatic arthritis [13].

\section{Aim}

Therefore, we aimed to investigate whether MPV is valuable in evaluating the course of psoriasis vulgaris (PV) and psoriatic arthritis (PA) or not.

Address for correspondence: Meliha Merve HIZ, Department of Medical Biology, Faculty of Medicine, Çanakkale Onsekiz Mart University, 17100 Çanakkale, Turkey, phone: +90 028621800 18- 2218, e-mail: mervemeliha@comu.edu.tr Received: 2.02.2016, accepted: 20.04.2016. 


\section{Material and methods}

This study was conducted at the Çanakkale Onsekiz Mart University, Faculty of Medicine, Physical Medicine and Rehabilitation Department in collaboration with the Department of Dermatology between 2012 and 2015. The case files of the patients diagnosed with psoriasis and psoriatic arthritis, who applied to our university hospital were reviewed retrospectively. Patients using drugs that impair the platelet function were excluded from the study. A total of 344 psoriasis patients were scanned and 41 patients with psoriasis and 116 patients with psoriatic arthritis met the adequate criteria and were included into the study. The demographic data of patients, duration of disease, psoriasis severity score (PASI), and laboratory results were recorded. Completely healthy volunteers were included into the control group. The local ethics committee approved the study. All participants gave their informed consent before taking part in the study. Reference range of MPV was 7.4 to $10.4 \mathrm{fl}$.

\section{Statistical analysis}

All obtained data were recorded on the SPSS 19.0 program. The variables normal distribution was examined using the Kolmogorov-Smirnov test. The mean, standard deviation, median, minimum and maximum values, frequency and percentages were used in the presentation of the descriptive data. The Kruskal-Wallis analysis of variance was used for abnormal distribution of the variables for comparison between the groups. Mann Whitney $U$ was used in independent groups for the comparison of averages of patient and control groups. The relationship between continuous variables in the patient group was examined using the Spearman's rank correlation test. Dependent and independent variables in the univariate analysis were examined using the $\chi^{2}$ test. Because the age variable was normally distributed among three groups (control and patients with psoriasis and without psoriasis, we used One-Way ANOVA test. The difference between groups was examined using Tukey post-hoc test. It was considered statistically significant when the $p$-value was below 0.05 .

\section{Results}

In our study, the data of 247 participants (116 psoriatic arthritis (68 females; 58.1\%) and 41 psoriasis (19 females; $46.3 \%$ ) and 90 control (55 females; 61.1\%) groups) were analyzed retrospectively. There was no significant difference between the groups in terms of gender ( $p=$ 0.276). The mean age of participants is as follows: in the psoriatic arthritis group $-47.53 \pm 14.03$, psoriasis group $-37.66 \pm 14.63$ and in the control group $-40.70 \pm 14.16$. While there was no statistically significant difference in the mean age of the psoriasis group as compared to the control group ( $p=0.491)$; the mean age of the psoriatic arthritis group was significantly higher than the control group $(p<0.05)$. The mean age of onset in the psoriatic arthritis group was significantly higher compared to the psoriasis group. There were no differences in duration of disease or family history of psoriasis between PV and PA group. The demographic features are shown in Table 1. There was no difference between PS and PA group for smoking, diabetes, hypertension and presence of heart disease (Table 2).

Table 1. Demographic features of patients with psoriasis and psoriatic arthritis

\begin{tabular}{|c|c|c|c|c|c|c|c|}
\hline \multirow[t]{2}{*}{ Parameter } & \multicolumn{2}{|c|}{$\begin{array}{l}\text { Patients without arthritis } \\
\qquad(N=41)\end{array}$} & \multicolumn{2}{|c|}{$\begin{array}{l}\text { Patients with arthritis } \\
\qquad(N=116)\end{array}$} & \multicolumn{2}{|c|}{$\begin{array}{l}\text { Control group } \\
\qquad(n=90)\end{array}$} & \multirow[t]{2}{*}{$P$-value } \\
\hline & $n$ & $\%$ & $n$ & $\%$ & $n$ & $\%$ & \\
\hline \multicolumn{8}{|l|}{ Gender: } \\
\hline Female & 19 & 46.3 & 68 & 58.6 & 55 & 61.1 & $0.276^{\star}$ \\
\hline Male & 22 & 53.6 & 48 & 41.4 & 35 & 38.9 & \\
\hline \multicolumn{8}{|c|}{ Family history of psoriasis: } \\
\hline Present & 6 & 25.0 & 28 & 32.2 & & & $0.499^{\star}$ \\
\hline \multirow[t]{2}{*}{ Absent } & 18 & 75.0 & 59 & 67.8 & & & \\
\hline & Mean \pm SD & $\begin{array}{c}\text { Median } \\
\text { (min.-max) }\end{array}$ & Mean \pm SD & $\begin{array}{c}\text { Median } \\
\text { (min.-max) }\end{array}$ & Mean \pm SD & $\begin{array}{c}\text { Median } \\
(\min .-\max )\end{array}$ & \\
\hline Mean age & $37.66 \pm 14.63$ & $36(9-66)$ & $47.53 \pm 14.03$ & $49(12-85)$ & $40.70 \pm 14.16$ & $38(18-81)$ & $<0.001^{\text {** }}$ \\
\hline Psoriasis duration & $16.53 \pm 11.98$ & $17(1-35)$ & $13.45 \pm 11.41$ & $10(1-55)$ & NA & NA & $0.401^{\star * *}$ \\
\hline PASI score & $12.48 \pm 8.39$ & $10.80(2.90-35.20)$ & $9.93 \pm 5.80$ & $8.50(1.20-27.00)$ & NA & NA & $0.400^{\star * *}$ \\
\hline Psoriasis onset age & $24.47 \pm 16.52$ & $19(5-62)$ & $35.43 \pm 15.97$ & $35(7-80)$ & NA & NA & $0.001^{\star \star \star}$ \\
\hline
\end{tabular}

${ }^{*}$ Pearson $\chi^{2}$, ${ }^{* *}$ one-way ANOVA, ${ }^{* * *}$ Mann-Whitney $U$ test. 
Table 2. Clinical features of patients with psoriasis and psoriatic arthritis

\begin{tabular}{|c|c|c|c|c|c|}
\hline \multirow[t]{2}{*}{ Variables } & \multicolumn{2}{|c|}{$\begin{array}{l}\text { Patients without arthritis } \\
\qquad(N=41)\end{array}$} & \multicolumn{2}{|c|}{$\begin{array}{l}\text { Patients with arthritis } \\
\qquad(N=116)\end{array}$} & \multirow[t]{2}{*}{$P$-value } \\
\hline & $n$ & $\%$ & $n$ & $\%$ & \\
\hline \multicolumn{6}{|l|}{ Diabetes: } \\
\hline Present & 7 & 19.4 & 29 & 80.6 & \multirow{2}{*}{0.311} \\
\hline Absent & 34 & 27.9 & 88 & 72.1 & \\
\hline \multicolumn{6}{|c|}{ Hypertension: } \\
\hline Present & 10 & 22.7 & 34 & 77.3 & \multirow{2}{*}{0.566} \\
\hline Absent & 31 & 27.2 & 83 & 72.8 & \\
\hline \multicolumn{6}{|c|}{ Coronary disease: } \\
\hline Present & 4 & 22.2 & 14 & 77.8 & \multirow{2}{*}{0.702} \\
\hline Absent & 37 & 26.4 & 103 & 73.6 & \\
\hline \multicolumn{6}{|l|}{ Smoking: } \\
\hline Present & 10 & 26.3 & 28 & 73.7 & \multirow{2}{*}{0.953} \\
\hline Absent & 31 & 25.8 & 89 & 74.2 & \\
\hline
\end{tabular}

*Pearson $\chi^{2}$.

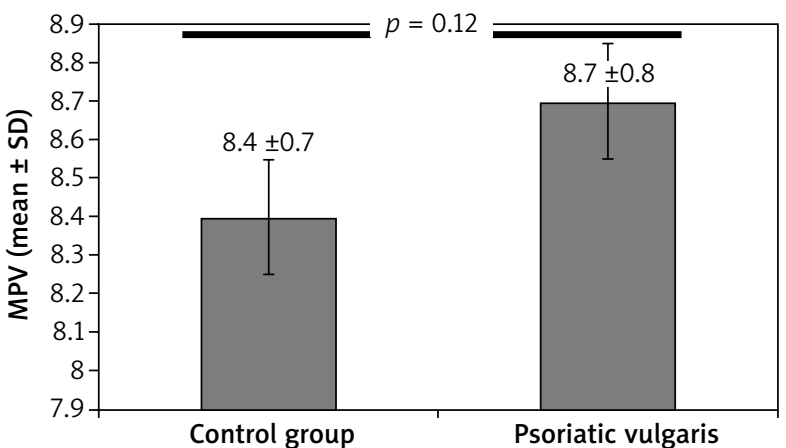

Figure 1. Comparison of mean platelet volume in patients with psoriasis and healthy individuals $(p=0.012)$

Both psoriasis group's MPV $(8.79 \pm 0.86)$ and the psoriatic arthritis group's MPV $(9.18 \pm 1.26)$ compared to the control group's MPV $(8.42 \pm 0.74)$ were significantly higher. The MPV level was significantly higher in psoriasis and of psoriatic arthritis group when compared with healthy individuals (Figures 1 and 2 respectively). The MPV of the psoriatic arthritis group was higher than the MPV of the psoriasis group (Table 3). Although the MPV level of the psoriatic arthritis group was higher than the psoriasis group, the difference was not significant (Figure 3). In addition, we identified a positive correlation between MPV and PASI scores $(r=0.165 ; p=0.046)$.

\section{Discussion}

Psoriasis is a common chronic inflammatory skin disease that is sometimes accompanied by joint prob-

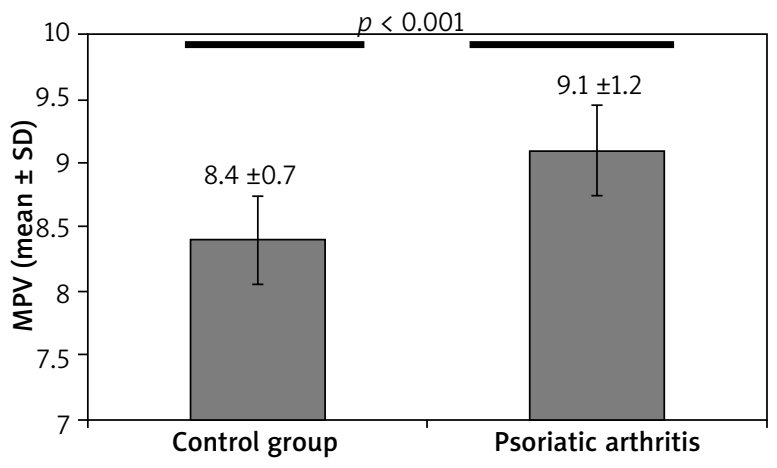

Figure 2. Comparison of mean platelet volume in patients with psoriatic arthritis and healthy individuals $(p<0.001)$

lems. Environmental and genetic factors as well as T cell activation play an important role in pathogenesis. Proinflammatory cytokines such as tumor necrosis factor $\alpha$ (TNF- $\alpha$ ), interleukin (IL)-17, IL-22, which are released after $T$ cell activation, and various chemokines and adhesion molecules, initiate the inflammatory process in psoriasis and psoriatic arthritis [14-16].

The platelets' role in the inflammatory process has recently become a highly documented topic. Platelets provide endothelial adhesion and aggregation that controls mediate hemostasis. It is also known to be influential in the regulation of inflammatory processes [17]. The MPV is an indicator of platelet activation and function. It has been used as a marker of inflammation in many diseases. The MPV activity index has been used as an indicator of anti-inflammatory efficacy in various studies [18-25]. There are conflicting results about the 
Table 3. Comparison of mean platelet volume (MPV) levels within the groups

\begin{tabular}{lccc}
\hline & $\begin{array}{c}\text { Control group } \\
(n=90)\end{array}$ & $\begin{array}{c}\text { Psoriasis vulgaris } \\
(n=41)\end{array}$ & $P$-value \\
\hline MPV (mean \pm SD) & $8.42 \pm 0.74$ & $8.79 \pm 0.86$ & $0.012^{*}$ \\
\hline MPV (mean \pm SD) & $\begin{array}{c}\text { Control group } \\
(n=90)\end{array}$ & $\begin{array}{c}\text { Psoriatic arthritis } \\
(n=116)\end{array}$ & $<0.001^{\star}$ \\
\hline & $8.42 \pm 0.74$ & $9.18 \pm 1.26$ & \\
\hline MPV (mean \pm SD) & $\begin{array}{c}\text { Psoriasis vulgaris } \\
(n=41)\end{array}$ & $\begin{array}{c}\text { Psoriatic arthritis } \\
(n=116)\end{array}$ & $0.072^{*}$ \\
\hline
\end{tabular}

*Independent samples test.

relationship between platelet activation and psoriasis. Tamagawa-Mineoka et al. found a correlation between platelet activation indicators and PASI scores in their studies on psoriasis patients that have shown platelet activation [26]. However, Saleh et al. could not find a statistically significant difference in MPV in either the patient or control groups, unlike in other studies [27]. Recently, Kim et al. indicated that a positive correlation between PASI and MPV as a result of their studies indicate higher MPV levels in moderate to severe psoriasis patients (PASI $\geq 10$ ) than mild psoriasis (PASI < 10) groups. Notwithstanding the increased MPV level was unrelated to higher PASI among psoriatic patients [28]. According to the results of our study there is a weak positive correlation between MPV and PASI. As known, the MPV level can be affected by lifestyle, diets and disease such as acute myocardial infarction (MI), hypercholesterolemia, diabetes mellitus, hypertension. Patients with psoriasis are more prone to obesity, hypercholesterolemia, diabetes mellitus and hypertension. For that reason, we think that the elevated MPV level may be used as an informative parameter but not the only indicator marker to evaluate psoriasis severity.

The MPV was also found higher in patients with psoriatic arthritis [29]. Canpolat et al. found the MPV level in the psoriatic arthritis group of $9.5 \pm 0.8 \mathrm{fl}$; psoriasis group of $8.0 \pm 0.7 \mathrm{fl}$; and the control group of $7.3 \pm 0.8 \mathrm{fl}$ $(p<0.01)$ [29]. The MPV levels of our study are $9.18 \pm 1.26 \mathrm{fl}$ in psoriatic arthritis; $8.76 \pm 0.86 \mathrm{fl}$ in psoriasis and 8.42 $\pm 0.74 \mathrm{fl}$ in control groups. Our findings suggest that the MPV was higher in both psoriasis and psoriatic arthritis groups compared with the control group and it is similar to studies done by Canpolat et al. Studies showed that the MPV value can be decreased by biological treatment of psoriasis and psoriatic arthritis [24, 28]. For that reason, we excluded the patients who have systemic treatment.

\section{Conclusions}

The most important result of our study was that the MPV level is higher in psoriasis and psoriatic arthritis and also that MPV correlated with PASI. In addition, the

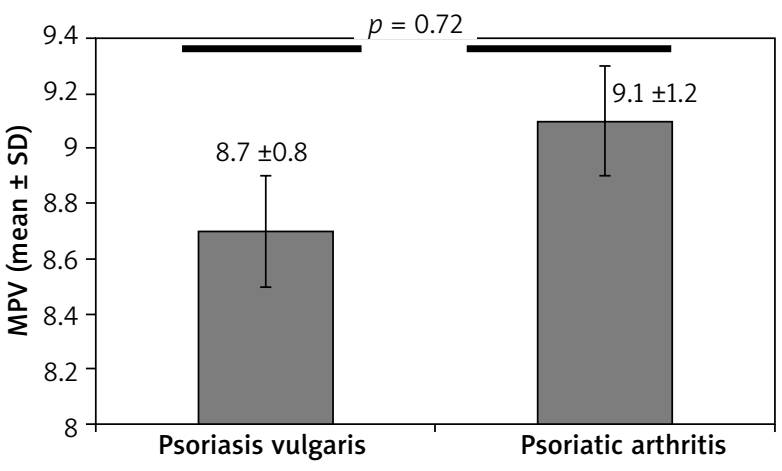

Figure 3. Comparison of mean platelet volume in patients with psoriasis vulgaris and psoriatic arthritis $(p=0.072)$

MPV level was even higher in patients with psoriatic arthritis than in the psoriasis group. This seems to support the thesis that severity of the clinical course leads to increased inflammation. Taken together, these observations suggest that MPV can be used as a follow-up parameter, especially in cases of severe psoriasis in terms of the development of arthritis. There is a need for future studies using large populations to investigate the MPV conditions associated with thrombosis and inflammation.

\section{Acknowledgments}

This study was conducted in Dermatology Department of Training and Research Hospital of Canakkale Onsekiz Mart University.

\section{Conflict of interest}

The authors declare no conflict of interest.

\section{References}

1. Parisi R, Symmons DP, Griffiths CE, et al. Global epidemiology of psoriasis: a systematic review of incidence and prevalence. J Invest Dermatol 2013; 133: 377-85. 
2. Rachakonda TD, Schupp CW, Armstrong AW, et al. Psoriasis prevalence among adults in the United States. J Am Acad Dermatol 2014; 70: 512-6.

3. Gisondi P, Tessari G, Conti A, et al. Prevalence of metabolic syndrome in patients with psoriasis: a hospital-based casecontrol study. Br J Dermatol 2007; 157: 68-73.

4. Christophers E. Comorbidities in psoriasis. Clin Dermatol 2007; 25: 529-34.

5. Chandran V, Gladman DD. How I would treat psoriatic arthritis? Acta Reum Port 2005; 30: 203-12.

6. Amor B, Dougados M, Listrat V, et al. Evaluation of the Amor criteria for spondylarthropathies and European Spondylarthropathy Study Group (ESSG). A cross-sectional analysis of 2,228 patients. Ann Med Interne 1991; 142: 85-9.

7. Gladman DD, Shuckett R, Russell ML, et al. Psoriatic arthritis (PSA) - an analysis of 220 patients. Q J Med 1987; 62: 127-41.

8. Çınar N, Bodur H, Eser F, et al. The prevalence and characteristics of psoriatic arthritis in patients with psoriasis in a tertiary hospital. Arch Rheumatol 2015; 30: 23-7.

9. Van der Loo B, Martin JF. A role for changes in platelet production in the cause of acute coronary syndromes. Arterioscler Thromb Vasc Biol 1999; 19: 672-9.

10. Huczek Z, Kochman J, Filipiak KJ, et al. Mean platelet volume on admission predicts impaired reperfusion and longterm mortality in acute myocardial infarction treated with primary percutaneous coronary intervention. J Am Coll Cardiol 2005; 46: 284-90.

11. Bath PM, Butterworth RJ. Platelet size: measurement, physiology and vascular disease. Blood Coagul Fibrinolysis 1996; 7: 157-61.

12. Pitchford SC, Page CP. Platelet activation in asthma: integral to the inflammatory response. Clin Exp Allergy 2006; 36: 399-401.

13. Işık S, Kılıç S, Öğretmen Z, et al. The correlation between the psoriasis area severity index and ischemia-modified albumin, mean platelet volume levels in patients with psoriasis. Adv Dermatol Allergol 2016; 33: 290-3.

14. Nast A, Rosumeck S, Sammain A, et al. S3-guidelines for the treatment of psoriasis vulgaris: methods report. J Dtsch Dermatol Ges 2011; 9: 64-84.

15. Schottelius AJ, Moldawer LL, Dinarello CA, et al. Biology of tumor necrosis factor-alpha implication for psoriasis. Exp Dermatol 2004; 13: 193-222.

16. Shabgah AG, Fattahi E, Shahneh FZ. Interleukin-17 in human inflammatory diseases. Postep Dermatol Alergol 2014; 31: 256-61.

17. Totani L, Evangelista V. Platelet-leukocyte interactions in cardiovascular disease and beyond. Arterioscler Thromb Vasc Biol 2010; 30: 2357361.

18. Park Y, Schone N, Harris W. Mean platelet volume as an indicator of platelet activation: methodological issues. Platelets 2002; 13: 301-6.

19. Chu SG, Becker RC, Berger PB, et al. Mean platelet volume as a predictor of cardiovascular risk: a systematic review and meta-analysis. J Thromb Haemost 2010; 8: 148-56.

20. Gasparyan AY, Ayvazyan L, Mikhailidis DP, et al. Mean platelet volume: a link between thrombosis and inflammation? Curr Pharm Des 2011; 17: 47-58.

21. Pamuk GE, Vural O, Turgut B, et al. Increased platelet activation markers in rheumatoid arthritis: are they related with subclinical atherosclerosis? Platelets 2008; 19: 146-54.

22. Wang F, Wang NS, Yan CG, et al. The significance of platelet activation in rheumatoid arthritis. Clin Rheumatol 2007; 26: 768-71.
23. Kisacik B, Tufan A, Kalyoncu U, et al. Mean platelet volume (MPV) as an inflammatory marker in ankylosing spondylitis and rheumatoid arthritis. Joint Bone Spine 2008; 75: 291-4.

24. Capo A, Di Nicola M, Auriemma M, et al. Mean platelet volume variation after biologic therapy in psoriasis and psoriatic arthritis. Eur J Dermatol 2014; 24: 133-5.

25. Gasparyan AY, Sandoo A, Stavropoulos-Kalinoglou A, et al. Mean platelet volume in patients with rheumatoid arthritis: the effect of anti-TNF-alpha therapy. Rheumatol Int 2010; 30: 1125-9.

26. Tamagawa-Mineoka R, Katoh N, Kishimoto S, et al. Platelet activation in patients with psoriasis: increased plasma levels of platelet-derived microparticles and soluble P-selectin. J Am Acad Dermatol 2010; 62: 621-6.

27. Saleh HMA, Attia EAS. Onsy AM, et al. Platelet activation: a link between psoriasis per se and subclinical atherosclerosis - a case-control study. Br J Dermatol 2013; 169: 68-75.

28. Kim DS, Lee J, Kim SH, et al. Mean platelet volume is elevated in patients with psoriasis vulgaris. Yonsei Med J 2015; 56: 712-8.

29. Canpolat F, Akpinar H, Eskioğlu F, et al. Mean platelet volume in psoriasis and psoriatic arthritis. Clin Rheumatol 2010; 29: 325-8. 